\title{
Effects of Twice-Weekly Intense Aerobic Exercise inQ1 Early Subacute Stroke: A Randomized Controlled Trial
}

\author{
Klas Sandberg, Marie Kleist, Lars Falk and Paul Enthoven
}

\section{Linköping University Post Print}

\section{Tweet}

N.B.: When citing this work, cite the original article.

Original Publication:

Klas Sandberg, Marie Kleist, Lars Falk and Paul Enthoven, Effects of Twice-Weekly Intense Aerobic Exercise inQ1 Early Subacute Stroke: A Randomized Controlled Trial, 2016, Archives of Physical Medicine and Rehabilitation.

http://dx.doi.org/10.1016/j.apmr.2016.01.030

Copyright: WB Saunders

http://www.elsevier.com/

Postprint available at: Linköping University Electronic Press

http://urn.kb.se/resolve?urn=urn:nbn:se:liu:diva-128225 


\section{Aerobic Exercise in Early Subacute Stroke}

\section{Effects of Twice-Weekly Intense Aerobic Exercise in Early Subacute Stroke:}

\section{A Randomized Controlled Trial}

Klas Sandberg MSc, RPT ${ }^{\mathrm{a}, \mathrm{b}}$, Marie Kleist Bsc, RPT ${ }^{\mathrm{a},}$ Lars Falk MD, PhD ${ }^{\mathrm{c}, \mathrm{d},}$ Paul Enthoven $\mathrm{RPT}, \mathrm{PhD}^{\mathrm{c}, \mathrm{e}}$

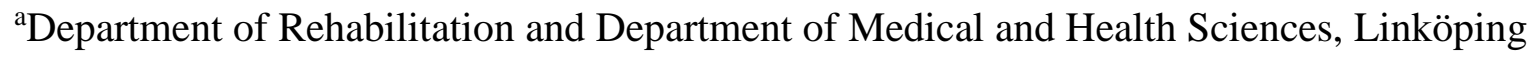
University, Norrköping, Sweden, ${ }^{b}$ Department of Internal Medicine, Vrinnevi Hospital, Norrköping, Sweden, ${ }^{c}$ Research \& Development Unit of Local Health Care and Department of Medical and Health Sciences, Linköping University, Linköping, Sweden, ${ }^{\mathrm{d}}$ Department of Dermatology and Venereology, and Department of Clinical and Experimental Medicine, Linköping University, Linköping, Sweden, ${ }^{e}$ Department of Medical and Health Sciences, Linköping University, Linköping, Sweden.

Supported by the Swedish Stroke Association, Stockholm, Sweden; the Henrik and Ella Margareta Ståhl Foundation, Norrköping, Sweden; the Medical Research Council of Southeast Sweden (FORSS), Sweden; and the Research and Development Council, Local Health Care, Norrköping, Sweden.

Clinical Trial Registration No.: NCT02107768.

Disclosures: none.

Archives of Physical Medicine and Rehabilitation 2016

0003-9993/16/\$36 - see front matter (C) 2016 by the American Congress of Rehabilitation Medicine

http://dx.doi.org/10.1016/j.apmr.2016.01.030 


\begin{abstract}
Objective: To examine the effects of 12 weeks of twice-weekly intensive aerobic exercise on physical function and quality of life after subacute stroke.

Design: Randomized controlled trial.

Setting: Ambulatory care.

Participants: Patients $(\mathrm{N}=56 ; 28$ women) aged $\leq 50$ years who had a mild stroke $(98 \%$ ischemic) and were discharged to independent living and enrolled 20 days (median) after stroke onset.
\end{abstract}

Interventions: Sixty minutes of group aerobic exercise, including 2 sets of 8 minutes of exercise with intensity up to exertion level 14 or 15 of 20 on the Borg rating of perceived exertion scale, twice weekly for 12 weeks $(n=29)$. The nonintervention group $(n=27)$ received no organized rehabilitation or scheduled physical exercise.

Main Outcome Measures: Primary outcome measures included aerobic capacity on the standard ergometer exercise stress test (peak work rate) and walking distance on the 6-minute walk test (6MWT). Secondary outcome measures included maximum walking speed for 10m, balance on the timed Up and Go (TUG) test and single leg stance (SLS), health-related quality of life on the European Quality of Life Scale (EQ-5D), and participation and recovery after stroke on the Stroke Impact Scale (SIS) version 2.0 domains 8 and 9. Participants were evaluated pre- and postintervention. Patient-reported measures were also evaluated at 6-month follow-up.

Results: The following improved significantly more in the intervention group (pre- to postintervention): peak work rate (group x time interaction, $P=.006), 6 \mathrm{MWT}(P=.011)$, maximum walking speed for 10m $(P<.001)$, TUG test $(P<.001)$, SLS right and left (eyes open) $(P<.001$ and $P=.022$, respectively), and SLS right (eyes closed) $(P=.019)$. Aerobic exercise was associated with improved EQ-5D scores (visual analog scale, $P=.008$ ) and 
perceived recovery (SIS domain $9, P=.002$ ). These patient-reported improvements persisted at 6-month follow-up.

Conclusions: Intensive aerobic exercise twice weekly early in subacute mild stroke improved aerobic capacity, walking, balance, health-related quality of life, and patient-reported recovery.

Key Words: exercise, randomized trial, stroke, quality of life, rehabilitation

\section{List of abbreviations:}

EQ-5D: European Quality Of Life 5 Dimensions (Euroqol-5D)

HRQOL: Health-Related Quality Of Life

RPE: Ratings of Perceived Exertion

SIS: Stroke Impact Scale 2.0

SLS: Single Leg Stance

6MWT: 6-Minute Walk Test

TUG: Timed Up and Go

VAS: Visual Analog Scale 
The decrease in aerobic capacity after stroke continues during the subsequent six months and often remains decreased thereafter. Most patients do not spontaneously recover to the aerobic levels of comparable healthy subjects. ${ }^{1-4}$ The maximum oxygen uptake $\left(\mathrm{VO}_{2} \mathrm{max}\right)$ is reduced to $10-17 \mathrm{ml} / \mathrm{kg} / \mathrm{min}$ in the $0-30$ days after the stroke ${ }^{1-3}$ and does not increase to over 20 $\mathrm{ml} / \mathrm{kg} / \mathrm{min}$ after six months $;^{2}$ this is $25-45 \%$ lower than the $\mathrm{VO}_{2} \mathrm{max}$ in age-matched, healthy subjects. ${ }^{2}$ This reduction in $\mathrm{VO}_{2}$ max might affect rehabilitation of patients with stroke who have a greater need for aerobic capacity for walking and performing the activities of daily living. ${ }^{5}$ An early start to aerobic exercise in order to prevent reduced aerobic capacity could improve rehabilitation after stroke.

Aerobic exercise has a beneficial effect in chronic stroke. ${ }^{6-8}$ A systematic review showed beneficial effects even during sub-acute stages (i.e. 7 days to 6 months after stroke) with improvements of peak oxygen uptake and walking distance. ${ }^{9}$ However, the results on walking speed and balance were unclear or conflicting and the outcome on e.g. quality of life was not explored. There is a lack of exercise prescription and the range of possible benefits is not fully explored. ${ }^{9-11}$

Walking and balance are important functions to recover after stroke. ${ }^{12}$ Functional limitations frequently necessitate ongoing rehabilitation. ${ }^{13}$ Reduced aerobic capacity and muscle weakness impede participation in everyday physical and social activities, and impaired social communication ability further reduces quality of life. ${ }^{14}$ Patients with stroke report a lower quality of life than healthy individuals. ${ }^{15}$

According to the Swedish stroke register, only $15 \%$ of patients with mild to moderate stroke receive further rehabilitation after their discharge to independent living. ${ }^{16}$ At the stroke clinic of the present study, patients with mild stroke were usually discharged to independent living without further rehabilitation. All patients had a follow-up visit by their physician three months after discharge. 
The primary aim of the present randomized controlled trial was to determine whether 12 weeks of twice-weekly intensive aerobic exercise in the subacute phase after mild stroke improved aerobic capacity and walking distance. The secondary aims were to study the effects of this exercise program on walking speed, functional mobility and balance and on health-related quality of life (HRQOL) and social participation.

\section{Methods}

This study was a single-center, parallel randomized prospective controlled trial. The study was guided by the Consolidated Standards of Reporting Trials statement. The study was approved by the Regional Ethics Committee, Linköping, Sweden.

\section{Participants}

Patients were recruited from the stroke unit at Vrinnevi Hospital, Norrköping, Sweden, during 2011-2013. Written informed consent was obtained from the enrolled subjects. The subjects were $\geq 50$ years old, and there was no upper age limit. There was a structured rehabilitation program for those $<50$ years old, and their rehabilitation was carried out in another clinic. All subjects had a stroke that was diagnosed by a physician within three days prior to the request for inclusion. Subjects had to be able to walk more than 5 meters with or without support and to understand spoken and written instructions. Their impairments corresponded to mild stroke (NHISS <6). ${ }^{17,18}$ Exclusion criteria were medical or neurological diseases that could either be a risk or making the training program difficult to fulfill. This judgement was made by the treating physician. 


\section{Procedures}

At the start of the study (pre-intervention) and prior to randomization, aerobic capacity was measured using a standard exercise stress test in the Department of Clinical Physiology by unbiased investigators blinded to the randomization outcome. Other physical assessments (see below) were carried out in the stroke unit. The assessments were repeated after three months (post-intervention).

At pre-intervention, all patients received a questionnaire about HRQOL, social participation and their sense of recovery. Patients filled out the questionnaires at home and were asked to send them back to the clinic within two weeks. The second questionnaire was sent to the participants one week before the post-intervention assessment. The third questionnaire was sent six months after the start of the study (follow-up). The intervention started within three days after randomization. Randomization was performed by shuffling concealed envelopes that were then picked randomly.

\section{Intervention}

The American Heart Association recommends 20 to 60 minute sessions of aerobic exercise of training 3 to 7 days per week after stroke. ${ }^{19}$ The intensity should be $50-80 \%$ of the maximal heart rate (11-14 on the Borg Rating of Perceived Exertion (RPE) scale). ${ }^{19,20}$ After discharge to independent living, the intervention group began a 12-week training period that included twice-weekly 60-minute aerobic exercise sessions. The sessions were conducted at the hospital and included a maximum of 10 participants. New patients were included consecutively and continuously i.e. each patient exercised according to his or her ability. The exercise sessions were led by an experienced physiotherapist (MK or KS) or by both if the group had more than six patients. Music was used to guide the exercise intensity using different numbers of beats per minute. The individual exercise intensity was adapted during 
each session by adjusting the load or the cycling speed so that the exercise goals were achieved. If the patients did not spontaneously reach the target intensity, they were given verbal encouragement. During exercise weeks 1,6, and 9, the participants carried heart rate monitors ${ }^{\mathrm{a}}$ to help them achieve an exercise intensity that was within the prescribed target heart rate range. The monitors also made the participants aware of the degree of effort that was required to reach the target range. Attendance at exercise sessions was recorded in the exercise log.

\section{Aerobic exercise program}

Each 60-minute session had five parts: (1) a 15-minute warm-up that included sitting, standing, and walking; (2) 8 minutes of high-intensity aerobic exercise on an ergometer cycle; (3) 10 minutes of lower-intensity mixed exercises that were intended to increase the flexibility of large muscle groups while sitting, standing, and walking; (4) 8 minutes of high-intensity aerobic exercise on an ergometer cycle; (5) a 15-minute cool-down in different positions.

We calculated that it should take a total of 4 minutes to move between exercise stations during the session.

\section{Intervention goals}

Each patient was given two fitness goals for each exercise session. First, during parts 1, 3, and 5, the goal was to reach a light-to-moderate training level RPE $11-13 / 20^{20}$, that corresponded to $\geq 50 \%$ of the estimated maximum oxygen uptake and to $60 \%$ of the maximum heart rate. ${ }^{11,20}$ Second, during parts 2 and 4 of the exercise program, the goal was to reach an exertion level RPE $14-15 / 20^{20}$ that corresponded to $\geq 75 \%$ of the estimated maximum oxygen uptake, and to $80 \%$ of the maximum heart rate. ${ }^{11,20}$ 
The patients were encouraged to try to return to their previous activity level as soon as possible.

\section{Control}

The nonintervention group did not receive any kind of rehabilitation. The subjects received general advice about physical training and activity and were encouraged to try to return to their previous activity level as soon as possible. At our hospital, this was considered standard care for patients with mild impairments after stroke when they were discharged. There was no monitoring or estimation of the participants' physical activities during the study period.

\section{Primary outcome measures}

There were two primary outcome measures. Aerobic capacity was measured with a symptomlimited graded cycle ergometer test (Peak WR). ${ }^{21}$ This standard exercise stress test is used worldwide and has high validity and good to excellent reliability. ${ }^{22,23}$ Walking distance was measured with the 6-Minute Walk Test (6MWT), which is a commonly used test for assessing the physical performance of people with stroke. ${ }^{24}$

\section{Secondary outcome measures}

Walking speed was assessed by the Maximum Walking Speed 10 meters test (MWS10m), ${ }^{14,25,26}$ which has high intrarater reliability and validity in patients with stroke. ${ }^{25}$ The Timed Up and Go test (TUG) ${ }^{27}$ was used for testing functional mobility. The test has excellent reliability and validity. ${ }^{28,29}$ Balance was determined by the Single Leg Stance (SLS) test. $^{30-32}$ 
HRQOL was estimated using the Euroqol-5D (EQ-5D) index and a visual analog scale (VAS). ${ }^{33-34}$ The self-reported Stroke Impact Scale 2.0 (SIS) was used to measure participation in daily activities (domain 8) and recovery after stroke (domain 9). The SIS is valid, reliable, and sensitive to change. ${ }^{35}$

\section{Statistical analysis}

The sample size calculation was based on the most important primary outcome measure 6MWT. Using a two-tailed test with a type I error of 0.05 and a power of $80 \%$, a clinically significant difference between the intervention and nonintervention group (improvement of 50 $\mathrm{m}(\mathrm{SD} 53 \mathrm{~m})$ for the $6 \mathrm{MWT}$ would be detected with a minimum sample of 20 subjects per group. ${ }^{36}$ Considering possible dropouts, the primary study goal was to include at least 25 patients per group.

The descriptive data are reported as mean \pm standard deviation (SD). The Student $t$-test, chisquare test, and Fisher exact test were used for within-group and between-group comparisons as appropriate. Differences within and between groups over time were examined using a mixed design repeated measures ANOVA (2 groups $\mathrm{x} 2$ time points). Cohen $d$ effect sizes and 95\% confidence intervals were calculated using R software ${ }^{\mathrm{b}}$ with the compute.es package. ${ }^{37}$ The following interpretation for the magnitude of the effect size $r$ is suggested: $0-.1$, no effect; .1-.4, a small effect; .5-.7, an intermediate effect; .8 and higher, a large effect. ${ }^{39}$ All other statistical analyses were conducted using SPSS version 22. ${ }^{\mathrm{c}}$ The level of significance was set at .05 .

\section{Results}

Between 2011 and 2013, 100 patients were assessed for study eligibility. Of these, 11 patients did not meet the inclusion criteria due to a new stroke or other disease. The exclusion criteria 
and the reasons why patients declined participation are shown in figure 1 . The study included 56 patients, 29 patients in the intervention group and 27 patients in the nonintervention group (see figure 1 and table 1 ). The patients were randomized in the early subacute phase (median 20 days) after stroke onset. Recruitment stopped after 56 subjects enrolled because of a change in the clinical routine regarding when the definite diagnosis of stroke was determined by the physician, which caused a delay and was an obstacle to including patients within the desired period.

The groups did not differ with respect to their demographic and clinical characteristics at pre-intervention (see table 1 and 2). The intervention attendance rate was $79 \%$, with a median of 19 exercise sessions per patient. No adverse events or side effects were reported. There were two dropouts (see figure 1). All subjects reached the estimated exercise goal according to the RPE scale during their training sessions.

\section{Primary outcome measures}

Both aerobic capacity (peak WR, $P=.006)$ and walking distance (6MWT, $P=.011$ ) increased significantly more in the intervention group versus the nonintervention group postintervention (group x time effect, see table 2).

\section{Secondary outcome measures}

Some secondary outcome measures, including the MWS10m $(P<.001)$, TUG $(P<.001)$, SLS with the right or left leg with both eyes open $(P<.001$ and $P=.022$ respectively), and SLS with the right leg with eyes closed $(P=.019)$ improved significantly more in the intervention group between pre-intervention and post-intervention (see table 2). During the same period, no improvements were seen in the nonintervention group (see table 2). 
The total group improved over time in terms of the self-reported measures EQ-5D VAS, participation, and recovery (time effect $\mathrm{P}<.001$, see table 2 ). For the EQ-5D VAS $(F(1.67,76.76)=5.61, P=.008)$ and SIS recovery $(F(1.59,80.97)=7.55, P=.002)$ the intervention group improved significantly more than the nonintervention group between preto post-intervention (table 2), while this was not the case for the EQ-5D Index or the SIS participation.

However, none of the four self-reported measures from the questionnaire at the 6-month follow-up showed any further significant improvements between post-intervention and the 6month follow-up (see table 3).

\section{Discussion}

This single-center randomized controlled study showed that early intensive aerobic exercise twice weekly for 12 weeks during the subacute stage of mild stroke could improve patients' physical performance and quality of life. To our knowledge, this is the first study of subacute mild stroke that found significant improvements "Within-subjects effects*group" (group x time) in aerobic capacity, walking distance, walking speed, functional mobility, balance, HRQOL, and a sense of recovery after aerobic exercise. Improvements in aerobic capacity and walking capacity after aerobic exercise have been shown previously in chronic stroke. ${ }^{6,7}$ Aerobic exercise in the early subacute phase of the disease in the present and other studies showed similar improvements in aerobic capacity. ${ }^{39,40}$ A study by MacKay-Lyons and Makrides found that $16.9 \%$ of patients with mild to severe stroke showed spontaneous recovery of peak aerobic capacity during the first 6 months after stroke. ${ }^{2}$ However, in the current study, there was almost no spontaneous recovery in the nonintervention group 3 
months post-intervention, which could have an impact on daily activities ${ }^{5}$ even in a longer perspective.

The present study had a different study design and all patients had a mild stroke, which complicates comparison with other studies..$^{9,39-41}$ One study, which used a treadmill as a training tool and required a lower level of exercise exertion, showed no differences between groups. ${ }^{41}$ The use of leg cycle ergometry for both training and assessment in the present study may allow the participants to perform better than if they used a treadmill. The improvement in walking distance (6MWT) in the exercise group was nearly twice as great as the established minimal clinical difference of 54 meters,${ }^{24}$ and the mean walking distance in the intervention group post-treatment was comparable to that of age-related healthy individuals. Tang. ${ }^{40} \mathrm{Katz}-$ Leurer. ${ }^{40}$ and colleagues found no significant difference between groups in terms of walking distance. Compared to the present study, the studies by Tang. ${ }^{40}$ and Katz-Leurer. ${ }^{40}$ and colleagues used lower intensity exercise and shorter exercise periods.

The walking speed improvement measured by MWS10m in the present study in the intervention group is not in line with comparable studies, ${ }^{39,40}$ which found no statistically significant results in favour of early aerobic exercise. Similarly, the improvements in functional mobility measured by TUG in the present study have not been seen in other studies. One other study also showed that exercise improved balance, but the results were not comparable overall due to differences in measurement methods. ${ }^{9,42}$ The repetitive motions of ergometer cycling positively affect walking ability and balance, which could be an important factor. $^{43}$

A meta-analysis by Chen and Rimmer of studies of patients with chronic stroke showed the benefits of aerobic exercise combined with strength exercise on HRQOL, while aerobic exercise alone did not have these benefits. ${ }^{15}$ In a study of patients in the subacute phase of stroke, aerobic exercise alone had no significant effect on HRQOL. ${ }^{40}$ In the present study, the 
improvements in HRQOL and recovery in the intervention group were achieved between preintervention and post-intervention, but there were no further improvements at the 6-month follow-up. It is not known whether the patients continued to train by themselves after the intervention. The stagnation in the reported HRQOL and in recovery may suggest that a longer and continuing aerobic exercise program could be beneficial.

The American Heart Association guidelines recommend training three to seven times per week. ${ }^{19}$ Adherence to training is low, however, when these guidelines are applied in clinical practice. ${ }^{44-46}$ In a pilot study we tested a design with more than two exercise sessions per week, but this design failed due to low adherence (K. Sandberg, M. Kleist, unpublished data, 2008). The present study, with exercise sessions twice a week, had a high adherence rate, suggesting that low training frequency with high aerobic exercise intensity may be optimal.

\section{Study limitations}

Approximately a third of the approached patients declined to participate in the study, citing transport problems or other issues. It is possible that those who agreed to participate in this exercise study were mainly patients with an interest in training. However, since there were almost no dropouts in the nonintervention group, this may not be the case. The previous fitness level, training activities or functional performance of the patients prior to the stroke were not registered, and this may have had an impact on the differences between the groups. The present study did not gather any information about each patient's activity levels during and after the intervention. A larger study population is probably needed to detect possible differences in, for example, self-rated social participation. In this study, multiple outcome measures were reported, which might increase the possibility of type I error (ie, saying there is a difference when there is not one). However, there is conflicting advice how to treat this. ${ }^{47}$ Furthermore, the effect sizes provide important additional information and the outcomes for 
the primary outcome measures are fairly clear. In this study, only patients $\geq 50$ years were accepted because of the local organization of neurological care, and this limits the generalizability of the study.

\section{Conclusion}

Patients with a mild stroke can benefit from intensive aerobic exercise twice weekly for 12 weeks in the early subacute phase. We found that intensive aerobic exercise improved aerobic capacity, walking, balance, HRQOL, and a sense of recovery in the intervention group compared with the nonintervention group, who were discharged to independent living without any specific exercise instructions. More research is needed to optimize the training protocol, and future studies should examine whether exercise continued beyond three months could improve outcomes further. Finally, studies should investigate whether patients with more severe stroke also benefit from early physical exercise.

\section{Suppliers}
a. Polar RS800CX; Polar Electro OY.
b. R software; R Core Team.
c. SPSS version 22; SPSS.

\section{Corresponding author}

Klas Sandberg, MSc, RPT, Vrinnevi Hospital, SE-601 82 Norrköping, Sweden

E-mail address: klas.sandberg@regionostergotland.se

\section{Acknowledgements}

We thank the staff at the Stroke Department and Department of Clinical Physiology, Vrinnevi Hospital, Norrköping, Sweden for contributing in inclusion and testing of patients. We also thank Henrik Magnusson, MSc, Linköping University, for statistical advice and Erwin E. Schmitz, MS, for help with data processing. 



\section{References}

1. Kelly JO, Kilbreath SL, Davis GM, Zeman B, Raymond J. Cardiorespiratory fitness and walking ability in subacute stroke patients. Arch Phys Med Rehabil 2003;84:1780-5.

2. Mackay-Lyons MJ, Makrides L. Longitudinal changes in exercise capacity after stroke. Arch Phys Med Rehabil 2004;85:1608-12.

3. Tang A, Sibley KM, Thomas SG, McIlroy WE, Brooks D. Maximal exercise test results in subacute stroke. Arch Phys Med Rehabil 2006;87:1100-5.

4. Potempa K, Lopez M, Braun LT, Szidon JP, Fogg L, Tincknell T. Physiological outcomes of aerobic exercise training in hemiparetic stroke patients. Stroke 1995;26:1015.

5. Danielsson A, Sunnerhagen KS. Oxygen consumption during treadmill walking with and without body weight support in patients with hemiparesis after stroke and in healthy subjects. Arch Phys Med Rehabil 2000;8:953-7.

6. Gordon CD, Wilks R, McCaw-Binns A. Effect of aerobic exercise (walking) training on functional status and health-related quality of life in chronic stroke survivors: a randomized controlled trial. Stroke 2013;44:1179-81.

7. Macko RF, Ivey FM, Forrester LW, Hanley D, Sorkin JD, Katzel LI, et al. Treadmill exercise rehabilitation improves ambulatory function and cardiovascular fitness in patients with chronic stroke: a randomized, controlled trial. Stroke 2005;36:2206-11.

8. Tang A, Marzolini S, Oh P, McIlroy WE, Brooks D. Feasibility and effects of adapted cardiac rehabilitation after stroke: a prospective trial. BMC Neurol 2010;10:40.

9. Stoller O, de Bruin ED, Knols RH, Hunt KJ. Effects of cardiovascular exercise early after stroke: systematic review and meta-analysis. BMC Neurol 2012;12:45. 
10. Mead G, Bernhardt J. Physical fitness training after stroke, time to implement what we know: more research is needed. Int J Stroke 2011;6:506-8.

11. Pollock ML, Gaesser GA, Butcher JD, Després J-P, Dishman RK, Franklin BA, et al. ACSM Position Stand: The Recommended Quantity and Quality of Exercise for Developing and Maintaining Cardiorespiratory and Muscular Fitness, and Flexibility in Healthy Adults. Med Sci Sports Exerc 1998;30:975-91.

12. Geyh S, Cieza A, Schouten J, Dickson H, Frommelt P, Omar Z, et al. ICF Core Sets for stroke. J Rehabil Med 2004;(44 Suppl):135-41.

13. Wade DT, Wood VA, Heller A, Maggs J, Langton Hewer R. Walking after stroke. Measurement and recovery over the first 3 months. Scand J Rehabil Med 1987;19:25-30.

14. Flansbjer UB, Downham D, Lexell J. Knee muscle strength, gait performance, and perceived participation after stroke. Arch Phys Med Rehabil 2006;87:974-80.

15. Chen MD, Rimmer JH. Effects of exercise on quality of life in stroke survivors: a metaanalysis. Stroke 2011;42:832-7.

16. The Swedish Stroke Register. Annual Stroke Report 2011 [In Swedish: Årsrapport. Rapport från Riksstroke för 2011]. Västerbottens läns landsting; 2012. WWW.riksstroke.org/sve

17. Brott T, Adams HP, Jr., Olinger CP, Marler JR, Barsan WG, Biller J, et al. Measurements of acute cerebral infarction: a clinical examination scale. Stroke 1989;20:864-70.

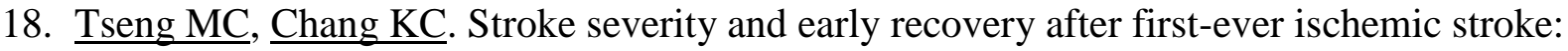
results of a hospital-based study in Taiwan. Health Policy 2006;79:73-8.

19. Gordon NF, Gulanick M, Costa F, Fletcher G, Franklin BA, Roth EJ, et al. Physical activity and exercise recommendations for stroke survivors: an American Heart Association scientific statement from the Council on Clinical Cardiology, Subcommittee 
on Exercise, Cardiac Rehabilitation, and Prevention; the Council on Cardiovascular Nursing; the Council on Nutrition, Physical Activity, and Metabolism; and the Stroke Council. Circulation 2004;109:2031-41.

20. Borg G. Perceived exertion as an indicator of somatic stress. Scand J Rehabil Med $1970 ; 2: 92-8$

21. Fletcher GF, Balady GJ, Amsterdam EA, Chaitman B, Eckel R, Fleg J, et al. Exercise standards for testing and training: a statement for healthcare professionals from the American Heart Association. Circulation 2001;104:1694-740.

22. Wasserman K, Hansen JE, Sue DY, Casaburi R, Whipp BJ. Principles of exercise testing \& interpretation: including pathophysiology and clinical applications. 3rd ed. Philadelphia: Lippincott Williams \& Wilkins; 1999.

23. Eng JJ, Dawson AS, Chu KS. Submaximal exercise in persons with stroke: test-retest reliability and concurrent validity with maximal oxygen consumption. Arch Phys Med Rehabil 2004;85:113-8.

24. Fulk GD, Echternach JL, Nof L, O'Sullivan S. Clinometric properties of the six-minute walk test in individuals undergoing rehabilitation poststroke. Physiother Theory Pract 2008;24:195-204.

25. Fulk GD, Echternach JL. Test-retest reliability and minimal detectable change of gait speed in individuals undergoing rehabilitation after stroke. J Neurol Phys Ther 2008;32:8-13.

26. Geroin C, Mazzoleni S, Smania N, Gandolfi M, Bonaiuti D, Gasperini G, et al. Systematic review of outcome measures of walking training using electromechanical and robotic devices in patients with stroke. J Rehabil Med 2013;45:987-96.

27. Podsiadlo D, Richardson S. The timed "Up \& Go": a test of basic functional mobility for frail elderly persons. J Am Geriatr Soc 1991;39:142-8. 
28. Jonsdottir J, Cattaneo D. Reliability and validity of the dynamic gait index in persons with chronic stroke. Arch Phys Med Rehabil 2007;88:1410-5.

29. Knorr S, Brouwer B, Garland SJ. Validity of the Community Balance and Mobility Scale in community-dwelling persons after stroke. Arch Phys Med Rehabil 2010;91:890-6.

30. Franchignoni F, Tesio L, Martino MT, Ricupero C. Reliability of four simple, quantitative tests of balance and mobility in healthy elderly females. Aging (Milano) 1998;10:26-31.

31. Bohannon RW, Walsh S, Joseph MC. Ordinal and timed balance measurements: reliability and validity in patients with stroke. Clin Rehabil 1993;7:9-13.

32. Flansbjer UB, Blom J, Brogardh C. The reproducibility of Berg Balance Scale and the Single-leg Stance in chronic stroke and the relationship between the two tests. PM\&R. 2012;4:165-70.

33. Szende A, Oppe M, Devlin NJ, EuroQol Group. EQ-5D value sets : inventory, comparative review, and user guide. Dordrecht: Springer; 2007.

34. Pinto EB, Maso I, Vilela RN, Santos LC, Oliveira-Filho J. Validation of the EuroQol quality of life questionnaire on stroke victims. Arq Neuropsiquiatr 2011;69:320-3.

35. Duncan PW, Wallace D, Lai SM, Johnson D, Embretson S, Laster LJ. The stroke impact scale version 2.0. Evaluation of reliability, validity, and sensitivity to change. Stroke 1999;30:2131-40.

36. Perera S, Mody SH, Woodman RC, Studenski SA. Meaningful change and responsiveness in common physical performance measures in older adults. J Am Geriatr Soc 2006;54:743-9.

37. R Core Team. R: A language and environment for statistical computing. R Foundation for Statistical Computing, Vienna, Austria. 2015. 
37. Cooper HM, Hedges LV, Valentine JC. The handbook of research synthesis and metaanalysis. 2nd ed. New York: Russell Sage Foundation; 2009.

38. Cohen J. Statistical power analysis for the behavioral sciences. 2nd ed. Hillsdale, N.J.: L. Erlbaum Associates; 1988.

39. Katz-Leurer M, Shochina M, Carmeli E, Friedlander Y. The influence of early aerobic training on the functional capacity in patients with cerebrovascular accident at the subacute stage. Arch Phys Med Rehabil 2003;84:1609-14.

40. Tang A, Sibley KM, Thomas SG, Bayley MT, Richardson D, McIlroy WE, et al. Effects of an aerobic exercise program on aerobic capacity, spatiotemporal gait parameters, and functional capacity in subacute stroke. Neurorehabil Neural Repair 2009;23:398-406.

41. da Cunha IT, Jr., Lim PA, Qureshy H, Henson H, Monga T, Protas EJ. Gait outcomes after acute stroke rehabilitation with supported treadmill ambulation training: a randomized controlled pilot study. Arch Phys Med Rehabil 2002;83:1258-65.

42. Katz-Leurer M, Sender I, Keren O, Dvir Z. The influence of early cycling training on balance in stroke patients at the subacute stage. Results of a preliminary trial. Clin Rehabil 2006;20:398-405.

43. Raasch CC, Zajac FE. Locomotor strategy for pedaling: muscle groups and biomechanical functions. J Neurophysiol 1999;82:515-25.

44. MacKay-Lyons MJ, Makrides L. Cardiovascular stress during a contemporary stroke rehabilitation program: is the intensity adequate to induce a training effect? Arch Phys Med Rehabil 2002;83:1378-83.

45. Touillet A, Guesdon H, Bosser G, Beis JM, Paysant J. Assessment of compliance with prescribed activity by hemiplegic stroke patients after an exercise programme and physical activity education. Ann Phys Rehabil Med 2010;53:250-65. 
46. Duncan PW, Horner RD, Reker DM, Samsa GP, Hoenig H, Hamilton B, et al. Adherence to postacute rehabilitation guidelines is associated with functional recovery in stroke. Stroke 2002;33:167-77.

47. Feise RJ. Do multiple outcome measures require p-value adjustment? BMC Med Res Methodol. 2002;2:8. 


\section{Flowchart of Study Participants}

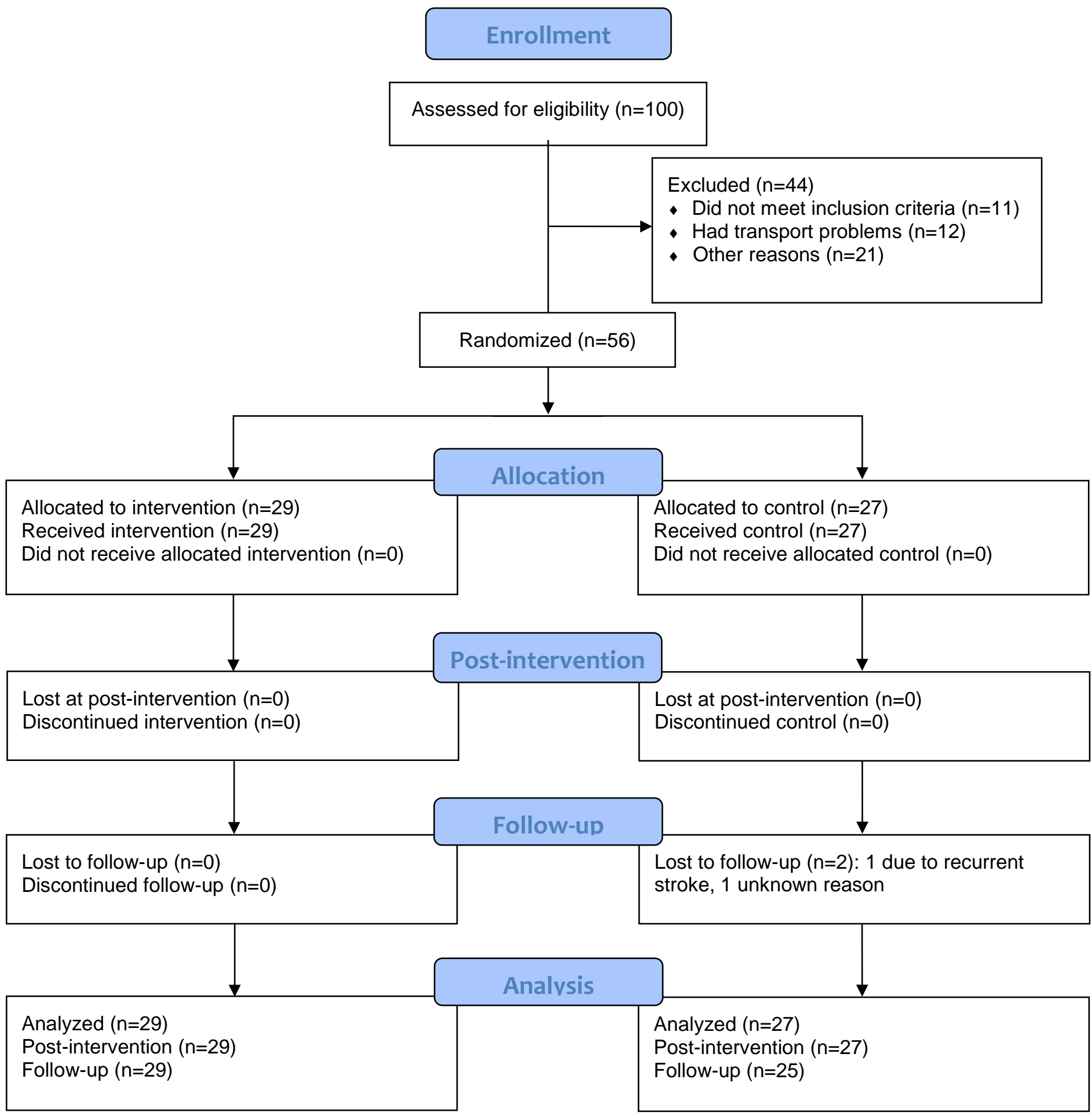

Figure 1. Flowchart of study participants through each stage of the trial. 
Table 1. Patient characteristics at pre-intervention

\begin{tabular}{|c|c|c|c|}
\hline Variable & $\begin{array}{l}\text { Intervention } \\
\text { group } \\
(\mathrm{n}=29)\end{array}$ & $\begin{array}{l}\text { Nonintervention } \\
\text { group } \\
(\mathrm{n}=27)\end{array}$ & $P$ \\
\hline \multicolumn{4}{|l|}{ Age, years } \\
\hline Mean \pm SD & $71.3 \pm 7.0$ & $70.4 \pm 8.1$ & $.657 *$ \\
\hline Range & $61-84$ & $53-87$ & \\
\hline Sex, n $(\%)$ & & & $.789^{\dagger}$ \\
\hline Male & $14(48)$ & $14(52)$ & \\
\hline Female & $15(52)$ & $13(48)$ & \\
\hline Type of stroke, n (\%) & & & $.482^{\ddagger}$ \\
\hline Ischemic & $29(100)$ & $26(96.3)$ & \\
\hline Hemorrhagic & $0(0)$ & $1(3.7)$ & \\
\hline Side affected by symptoms, n (\%) & & & $.716^{*}$ \\
\hline Right & $16(55.2)$ & $12(44.4)$ & \\
\hline Left & $11(37.9)$ & $13(48.1)$ & \\
\hline Unknown & $2(6.9)$ & $2(7.4)$ & \\
\hline $\begin{array}{l}\text { Days from stroke onset to pre-intervention } \\
\text { walking and balance test. Mean } \pm \text { SD }\end{array}$ & $4.9 \pm 5.8$ & $6.3 \pm 7.3$ & $.418^{*}$ \\
\hline $\begin{array}{l}\text { Days from stroke onset to pre-intervention } \\
\text { standard exercise stress test. Mean } \pm \text { SD }\end{array}$ & $22.2 \pm 10.1$ & $22.8 \pm 10.8$ & $.839 *$ \\
\hline Use of walking aid at recruitment, $\mathrm{n}(\%)$ & & & .424 \\
\hline No & $24(82.8)$ & $25(92.6)$ & \\
\hline Yes & $5(17.2)$ & $2(7.4)$ & \\
\hline
\end{tabular}

Abbreviations: SD Standard Deviation

*Unpaired $t$ test

$\dagger$ Chi-squared test

†Fisher's exact test 
Table 2. Primary and secondary outcome measures. Comparisons between groups over the time period pre- to post-intervention.

\begin{tabular}{|c|c|c|c|c|c|c|}
\hline \multirow[b]{2}{*}{ Measures } & \multirow[b]{2}{*}{$\begin{array}{l}\text { Intervention } \\
\text { group } \\
(\mathrm{n}=29)\end{array}$} & \multirow[b]{2}{*}{$\begin{array}{l}\text { Noninterve } \\
\text { ntion group } \\
(\mathrm{n}=27)\end{array}$} & \multirow[b]{2}{*}{$\begin{array}{l}\text { Between-group } \\
\text { comparison }\end{array}$} & \multicolumn{3}{|c|}{ Mixed design repeated measures ANOVA } \\
\hline & & & & $\begin{array}{l}\text { Within-subjects effects } \\
\text { (time effect) }\end{array}$ & $\begin{array}{l}\text { Within-subjects } \\
\text { effects*group } \\
\text { (group x time) }\end{array}$ & $\begin{array}{l}\text { Between-subjects effects } \\
\text { (group effect) }\end{array}$ \\
\hline $\begin{array}{l}\text { Aerobic capacity, peak WR (watts), } \\
\mathrm{n}=28,25\end{array}$ & & & & $\begin{array}{l}F(1,51)=13.319, P=.001 \\
d=1(.42 \text { to } 1.59)\end{array}$ & $\begin{array}{l}F(1,51)=8.327, P=.006 \\
d=.79(.22 \text { to } 1.37)\end{array}$ & $\begin{array}{l}F(1,51)=.074, P=.787 \\
d=.07(-.48 \text { to } .63)\end{array}$ \\
\hline Pre-intervention & $113.9 \pm 27.6$ & $123.8 \pm 41.9$ & $\begin{array}{l}t=-1.027, d f=51, P=.309 \\
d=-.28(-.84 \text { to } .27)\end{array}$ & & & \\
\hline Post-intervention & $130.4 \pm 33.7$ & $125.8 \pm 42.9$ & $\begin{array}{l}t=.436, d f=51, P=.665 \\
d=.12(-.43 \text { to } .67)\end{array}$ & & & \\
\hline Change pre- to post-intervention & $16.4 \pm 11.0$ & $1.9 \pm 23.9$ & & & & \\
\hline $\begin{array}{l}\text { 6-Minute Walk Test (meters), } \\
\mathrm{n}=29,27\end{array}$ & & & & $\begin{array}{l}F(1,54)=28.771, P<.001 \\
d=1.43(.83 \text { to } 2.04)\end{array}$ & $\begin{array}{l}F(1,54)=6.930, P=.011 \\
d=.7(.15 \text { to } 1.26)\end{array}$ & $\begin{array}{l}F(1,54)=2.439, P=.124 \\
d=.42(-.12 \text { to } .96)\end{array}$ \\
\hline Pre-intervention & $394.7 \pm 114.7$ & $384.3 \pm 131.9$ & $\begin{array}{l}t=.315, d f=54, P=.754 \\
d=.08(-.45 \text { to } .62)\end{array}$ & & & \\
\hline Post-intervention & $499.8 \pm 93.1$ & $420.2 . \pm 131.6$ & $\begin{array}{l}t=2.626, d f=54, P=.011 \\
d=.7(.15 \text { to } 1.25)\end{array}$ & & & \\
\hline Change pre- to post-intervention & $105.1 \pm 79.5$ & $35.9 \pm 115.1$ & & & & \\
\hline $\begin{array}{l}\text { Maximum Walking Speed } 10 \text { meters } \\
\text { (seconds), } n=29,27\end{array}$ & & & & $\begin{array}{l}F(1,54)=20.742, P<.001 \\
d=1.22(.63 \text { to } 1.8)\end{array}$ & $\begin{array}{l}F(1,54)=17.694, P<.001, \\
d=1.12(.55 \text { to } 1.7)\end{array}$ & $\begin{array}{l}F(1,54)=.357, P=.553 \\
d=.16(-.38 \text { to } .7)\end{array}$ \\
\hline Pre-intervention & $8.2 \pm 3.0$ & $7.4 \pm 1.9$ & $\begin{array}{l}t=1.148, d f=54, P=.256 \\
d=.31(-.23 \text { to } .85)\end{array}$ & & & \\
\hline Post-intervention & $6.0 \pm 1.5$ & $7.4 \pm 1.8$ & $\begin{array}{l}t=-3.090, d f=54, P=.003 \\
d=.83(.27 \text { to } 1.38)\end{array}$ & & & \\
\hline Change pre- to post-intervention & $-2.2 \pm 2.2$ & $-.1 \pm 1.5$ & & & & \\
\hline $\begin{array}{l}\text { Timed up and go test (seconds), } \\
n=29,27\end{array}$ & & & & $\begin{array}{l}F(1,54)=28.468, P<.001 \\
d=1.43(.83 \text { to } 2.03)\end{array}$ & $\begin{array}{l}F(1,54)=14.397, P<.001 \\
d=1.01(.45 \text { to } 1.58)\end{array}$ & $\begin{array}{l}F(1,54)=.357, P=.553 \\
d=.16(-.38 \text { to } .7)\end{array}$ \\
\hline Pre-intervention & $12.3 \pm 5.5$ & $10.0 \pm 2.9$ & $\begin{array}{l}t=1.931, d f=42.93, P=.060 \\
d=.52(-.03 \text { to } 1.06)\end{array}$ & & & \\
\hline Post-intervention & $8.1 \pm 1.9$ & $9.3 \pm 2.6$ & $\begin{array}{l}t=-2.066, d f=54, P=.044 \\
d=.55(.01 \text { to } 1.1)\end{array}$ & & & \\
\hline Change pre- to post-intervention & $-4.2 \pm 4.5$ & $-.7 \pm 1.8$ & & & & \\
\hline
\end{tabular}


Single Leg Stance right (eyes open) (seconds), $\mathrm{n}=29,27$

Pre-intervention

\section{Post-intervention}

Change pre- to post-intervention

Single Leg Stance left (eyes open)

(seconds), $\mathrm{n}=29,27$

Pre-intervention

Post-intervention

Change pre- to post-interventio

Single Leg Stance right (eyes closed) (seconds), $\mathrm{n}=29,27$

Pre-intervention

\section{Post-intervention}

Change pre- to post-intervention

Single Leg Stance left (eyes closed) (seconds), $\mathrm{n}=29,27$

\section{Pre-intervention}

Post-intervention

Change pre- to post-intervention

EQ-5D index

$\mathrm{n}=28,22$

Pre-intervention

Post-intervention
$9.6 \pm 10.3$

$11.8 \pm 10.8$

$t=-.782, d f=54, P=.438$ $d=-.21(-.75$ to .33$)$

$20.0 \pm 10.6 \quad t=2.578, d f=54, P=.013$

$d=.69(.14$ to 1.24$)$

$10.4 \pm 10.5 \quad .9 \pm 7.6$

$F(1,54)=25.415, P<.001$

$t=.282, d f=54, P=.779$

$12.4 \pm 10.7$

$11.6 \pm 11.4$

$d=.08(-.46$ to .61$)$

$20.9 \pm 11.2$

$14.7 \pm 11.5$

$t=2.039, d f=54, P=.046$ $d=.55(0$ to 1.09$)$

$8.4 \pm 9.1$

$3.0 \pm 7.8$

$1.9 \pm 2$

$4.2 \pm 3.5$

$1.8 \pm 1.7$

$t=.228, d f=54, P=.820$,

$=.06(-.48$ to .6$)$

$t=2.135, d f=54, P=.037$,

$d=.57(.02$ to 1.12$)$

$2.2+2.7$

$6 \pm 2.3$

\section{$2.8 \pm 2.5$}

$4.5 \pm 4.6$

$2.0+1.9$

$27 \pm 2.6$

$t=1.433, d f=54, P=.158$

$d=.38$ (- .16 to .92 )

$t=1.790, d f=54, P=.079$,

$d=.48(-.07,1.02)$

$1.7 \pm 3.9$

$.7 \pm 2.1$

$.75 \pm .16$

$.81 \pm .2$

$.85 \pm .12$ $d=1.35(.75$ to 1.94$)$

$F(1,54)=20.878, P<.001$,

$d=1.22(.64$ to 1.81$)$

$F(1,54)=17.228, P<.001$

$d=1.11(.53$ to 1.69$)$

$F(1,54)=8.094, P=.006$

$d=.76(.21$ to 1.32$)$

$F(1,48)=.948, P=.335$,

$d=.28$ (- .30 to .85$)$ $t=-1.239, d f=48, P=.221$ $d=.35(-.22$ to .93$)$

$t=.964, d f=26.310, P=.344$,

$d=.27(-.3$ to .85$)$
$F(1,54)=14.958, P<.001$,

$d=1.03(.46$ to 1.61$)$

$F(1,54)=1.017, P=.318$ $d=.27(-.27$ to .81$)$

$F(1,54)=5.573, P=.022$ $d=.63(.08$ to 1.18$)$

$F(1,54)=1.606, P=.210$, $d=.34$ (- .2 to .88 )

\section{$F(1,54)=5.855, P=.019$}

$d=.65$ (.1 to 1.2 )

$F(1,54)=2.515, P=.119$, $d=.42$ (- .12 to .97 )

$F(1,54)=1.261, P=.266$ $d=.3(-.24$ to .84$)$

$F(1,54)=3.509, P=.066$ $d=.5(-.04$ to 1.05$)$
$F(1,48)=3.404, P=.071$, $d=.53$ (- .06 to 1.11 )

$F(1,48)=.001, \mathrm{P}=.969$ $d=.01$ ( -.56 to .58$)$ 
Change pre- to post-intervention EQ-5D VAS,

$\mathrm{n}=27,21$

Pre-intervention

Post-intervention

Change pre- to post-intervention

SIS (domain 8) Participation (0-100), $\mathrm{n}=28,23$

Pre-intervention

Post-intervention

Change pre- to post-intervention

SIS (domain 9) Recovery VAS (0-100), $\mathrm{n}=28,25$

Pre-intervention

Post-intervention

Change pre- to post-intervention
$.10 \pm .16$

$-.03 \pm .33$

(2)

$72.3 \pm 22.3$

$80.4 \pm 18.9$

$81.1 \pm 17.5$

$d=-.39(-.98$ to .2$)$

$15.0 \pm 19.2 \quad .7 \pm 17.7$

$t=1.446, d f=28.359, P=.159$,
$d=.42(-.17$ to 1.01$)$

$\begin{array}{lll}67.6 \pm 20.6 & 68.4 \pm 28.0 \quad \begin{array}{l}t=-.116, d f=39.510, P=.908, \\ d=-.03(-.6 \text { to } .53)\end{array} \\ 82.5 \pm 20.5 \quad 79.4 \pm 19.2 \quad \begin{array}{l}t=.547, d f=49, P=.587, \\ d=.15(-.41 \text { to } .72)\end{array}\end{array}$

$F(1,49)=20.411, \mathrm{P}<.001$,

$d=1.27(.65$ to 1.89 )

\section{$F(1,46)=8.443, P=.006$}

$d=.85(.23$ to 1.46$)$

$F(1,46)=6.975, P=.011$

$d=.77(.16$ to 1.37$)$

$F(1,46)=.058, P=.811$, $d=.07(-.52$ to .66$)$

$14.9 \pm 19.1 \quad 11.0 \pm 22.0$

$F(1,51)=12.948, P=.001$

$$
\begin{aligned}
& F(1,51)=12.948, \mathrm{P} \\
& d=.99(.41 \text { to } 1.58)
\end{aligned}
$$

$F(1,51)=11.147, \mathrm{P}=002$

$d=.93(.35$ to 1.51$)$

$F(1,51)=.438, \mathrm{P}=.511$

$t=-1.961, d f=51, P=.055$,

$73.2 \pm 19.7$

$83.4 \pm 17.9$

$d=-.54(-1.1$ to .02$)$

$89.2 \pm 8.6$

$84.0 \pm 15.4$

$t=1.506, d f=36.677, P=.141$,

$d=.41(-.14$ to .97$)$

$16.0 \pm 16.6 \quad .6 \pm 17.1$

Note. Values are mean \pm Standard Deviation (SD). Bold type: statistically significant differences $(P<.05)$.

Abbreviations: EQ-5D, European Quality of Life 5 Dimensions; VAS, Visual Analogue Scale; SIS, Stroke Impact Scale version 2; $d f$, degrees of freedom $d$, Cohen's $d$ effect size (95\% Confidence Interval).

Between-group comparisons were calculated using the unpaired $t$-test. Within- and between-subjects effects were calculated using mixed design repeated measures ANOVA. 
Table 3. Patient-reported outcome measures. Comparisons between groups over the time period post-intervention to 6-month follow-up.

\begin{tabular}{|c|c|c|c|c|c|c|}
\hline \multirow[b]{2}{*}{ Measures } & \multirow[b]{2}{*}{$\begin{array}{l}\text { Intervention } \\
\text { group } \\
(\mathrm{n}=29)\end{array}$} & \multirow[b]{2}{*}{$\begin{array}{l}\text { Noninterve } \\
\text { ntion group } \\
(\mathrm{n}=27)\end{array}$} & \multirow[b]{2}{*}{$\begin{array}{l}\text { Between-group } \\
\text { comparison }\end{array}$} & \multicolumn{3}{|c|}{ Mixed design repeated measures ANOVA } \\
\hline & & & & $\begin{array}{l}\text { Within-subjects effects } \\
\text { (time effect) }\end{array}$ & $\begin{array}{l}\text { Within-subjects } \\
\text { effects*group } \\
\text { (group x time) }\end{array}$ & $\begin{array}{l}\text { Between-subjects effects } \\
\text { (group effect) }\end{array}$ \\
\hline $\begin{array}{l}\text { EQ-5D index, } \\
\mathrm{n}=28,22\end{array}$ & & & & $\begin{array}{l}F(1,48)=1.231, P=.273 \\
d=.32(-.26 \text { to } .89)\end{array}$ & $\begin{array}{l}F(1,48)=.002, P=.961 \\
d=.01(-.56 \text { to } .59)\end{array}$ & $\begin{array}{l}F(1,48)=1.323, P=.256 \\
d=.33(-.25 \text { to } .90)\end{array}$ \\
\hline Post-intervention & $.85 \pm .12$ & $.78 \pm .31$ & $\begin{array}{l}t=.964, d f=26.310, P=.344 \\
d=.27(-.3 \text { to } .85)\end{array}$ & & & \\
\hline 6-month follow-up & $.88 \pm .18$ & $.82 \pm .27$ & $\begin{array}{l}t=.959, d f=33.921, P=.344 \\
d=.27(-.3 \text { to } .85)\end{array}$ & & & \\
\hline Change post-intervention to follow-up & $.03 \pm .17$ & $.03 \pm .22$ & & & & \\
\hline $\begin{array}{l}\text { EQ-5D VAS, } \\
\mathrm{n}=27,21\end{array}$ & & & & $\begin{array}{l}F(1,46)=2.718, P=.106 \\
d=.48(-.11 \text { to } 1.07)\end{array}$ & $\begin{array}{l}F(1,46)=.112, P=.739 \\
d=.1(-.49 \text { to } .68)\end{array}$ & $\begin{array}{l}F(1,46)=2.198, P=.145 \\
d=.43(-.16 \text { to } 1.02)\end{array}$ \\
\hline Post-intervention & $87.2 \pm 9.1$ & $81.1 \pm 17.5$ & $\begin{array}{l}t=1.446, d f=28.359, P=.159 \\
d=.42(-.17 \text { to } 1.01)\end{array}$ & & & \\
\hline 6-month follow-up & $89.6 \pm 11.3$ & $84.7 \pm 18.3$ & $\begin{array}{l}t=1.075, d f=31.367, P=.291 \\
d=.31(-.28 \text { to } .9)\end{array}$ & & & \\
\hline Change post-intervention to follow-up & $2.3 \pm 7.9$ & $3.5 \pm 16.2$ & & & & \\
\hline $\begin{array}{l}\text { SIS (domain 8) Participation (0-100), } \\
\mathrm{n}=28,23\end{array}$ & & & & $\begin{array}{l}F(1,49)=1.911, P=.173 \\
d=.39(-.18 \text { to } .96)\end{array}$ & $\begin{array}{l}F(1.49)=.058, P=.811 \\
d=.07(-.5 \text { to } .63)\end{array}$ & $\begin{array}{l}F(1,49)=.442, P=.509 \\
\mathrm{~d}=.19(-.38 \text { to } .75)\end{array}$ \\
\hline Post-intervention & $82.5 \pm 20.5$ & $79.4 \pm 19.2$ & $\begin{array}{l}t=.547, d f=49, P=.587 \\
d=.15(-.41 \text { to } .72)\end{array}$ & & & \\
\hline 6-month follow-up & $85.7 \pm 19.4$ & $81.7 \pm 21.5$ & $\begin{array}{l}t=.699, d f=49, P=.488 \\
d=.2(-.37 \text { to } .76)\end{array}$ & & & \\
\hline Change post-intervention to follow-up & $3.2 \pm 11.3$ & $2.3 \pm 16.7$ & & & & \\
\hline $\begin{array}{l}\text { SIS (domain 9) Recovery VAS (0-100), } \\
\mathrm{n}=28,25\end{array}$ & & & & $\begin{array}{l}F(1,51)=.918, P=.343 \\
d=.26(-.29 \text { to } .82)\end{array}$ & $\begin{array}{l}F(1,51)=.012, P=.914 \\
d=.03(-.52 \text { to } .58)\end{array}$ & $\begin{array}{l}F(1,51)=2.574, P=.115 \\
d=.44(-.12 \text { to } 1)\end{array}$ \\
\hline Post-intervention & $89.2 \pm 8.6$ & $84.0 \pm 15.4$ & $\begin{array}{l}t=1.506, d f=36.677, P=.141 \\
d=.41(-.14 \text { to } .97)\end{array}$ & & & \\
\hline 6-month follow-up & $91.1 \pm 8.5$ & $85.4 \pm 20.3$ & $\begin{array}{l}t=1.288, d f=31.482, P=.207 \\
d=.35(-.2 \text { to } .91)\end{array}$ & & & \\
\hline Change post-intervention to follow-up & $1.9 \pm 6.0$ & $1.5 \pm 17.3$ & & & & \\
\hline
\end{tabular}

Note. Values are mean \pm Standard Deviation $(\mathrm{SD})$. Bold type: statistically significant differences $(P<.05)$. 
Abbreviations: EQ-5D, European Quality of Life 5 Dimensions; VAS, Visual Analogue Scale; SIS, Stroke Impact Scale version 2; $d f$, degrees of freedom $d$, Cohen's $d$ effect size (95\% Confidence Interval).

Between-group comparisons were calculated using the unpaired $t$-test. Within- and between-subjects effects were calculated using mixed design repeated measures ANOVA. 